\title{
XXVII. The charges on ions
}

\section{John S. Townsend F.R.S.}

To cite this article: John S. Townsend F.R.S. (1904) XXVII. The charges on ions, Philosophical Magazine Series 6, 7:39, 276-281, DOI: 10.1080/14786440409463110

To link to this article: http://dx.doi.org/10.1080/14786440409463110

$$
\text { 册 Published online: } 15 \text { Apr } 2009 .
$$

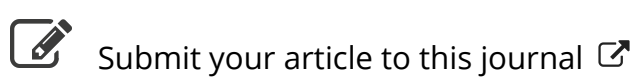

LII Article views: 6

Q View related articles 두 
It is clear from the figure that perfection of design has, in the model, been sacrificed for the sake of simplicity of construction. Instead of having holes bored in FH the slot should be extended to $\mathrm{F}$ and another slot cut between $\mathrm{G}$ and $\mathrm{H}$. A sliding focal pin could then be clamped in any position. Also the rhombus should have been shaped at the corners $A$ and $B$ so as always to leave sufficient space between the sides to allow of the pen $\mathrm{P}$ sliding right up to the corners, even if the rhombus is nearly closed.

To describe a parabola, $\mathrm{F}^{\prime}$ is made the focus, and $\mathrm{FH}$ is moved at right angles to itself, keeping it always parallel to its original direction. Under these circumstances $\mathbf{P}$ describes a parabola, and $G$ its directrix. I made no provision in $\mathrm{my}$ model for drawing parabolas, hut I found that it would describe a very fair parabola if the flat end of $F$ were made to slide along a fixed ruler.

I have not previously published any description of these compasses, as I hoped some time to improve the design and get a good working instrument made.

XXVII. The Charges on Ions. By . ToHv S. Townsend, F.R.S., Wykeham Professor of Physics, Oxford*.

THE relation between the charges on ions produced in gases by various methods is a matter of some importance, as the theory of electric currents in liquids and gases which is almost universally adopted is founded on the principle that all these small subdivisions of electricity with which the ions are charged are equal to or exact multiples of some charge which is absolutely fixed. The theory is supported by the phenomena which accompany the passage of electricity through liquids, and as is well known the charges on the ions are all exact multiples of the charge on the hydrogen ion in a liquid electrolyte. The theory also holds for gases ; and it can be proved that the charge on an ion produced by almost any of the known methods, in a gas, is identical with the charge on the hydrogen ion in a liquid electrolyte.

It is of interest to collect the results upon which this theory is founded, and to show to what degree of accuracy the atomic charge may be considered to be known.

If $\mathrm{E}$ is the charge on a hydrogen ion or atom in a liquid electrolyte, $\mathrm{N}$ the number of molecules per cubic centimetre

* Communicated by the Author. 
of a gas at $15^{\circ} \mathrm{C}$. and $760 \mathrm{~mm}$. pressure, then, since a known volume of hydrogen is evolved at the negative electrode when unit quantity of electricity passes through the liquid, the formula

$$
\mathrm{N} \times \mathrm{E}=1.22 \times 10^{10}
$$

is established, $\mathrm{E}$ being measured in electrostatic units.

If $e$ is the charge on an ion in a gas, $u$ its velocity when acted on by a force of one volt per centimetre, $K$ the rate of diffusion of ions in the gas, it can be shown that

$$
\mathrm{N} \times e=\frac{3 \times 10^{8} u}{\mathrm{~K}} .
$$

This formula is derived from the kinetic theory of gases by very simple considerations, it does not involve any assumption as to the distributions of the velocities of translation of the molecules, or the law of force between molecules during a collision. It may therefore be considered very reliable from a theoretical point of view.

The values of $\mathrm{K}$ and $u$ have been found experimentally in a large number of cases, so that the values of $\mathrm{N} \times e$ may be calculated. The mean values of $u$ for positive and negative ions produced by Röntgen rays in different gases have been found by Prof. Rutherford *. Anotber set of determinations of the velocities have been made by Prof. Zeleny $\dagger$, using a different method in which the velocities of the positive and negative ions have been determined separately.

The values of $u$ for ions produced by ultra-violet light have also been determined by Prof. Rutherford $\ddagger$.

The values of $K$ have been determined by the author for ions produced by Röntgen rays, ultra-violet light, and radioactive substances $\S$.

Taking the values of $u$ given by Prof. Rutherford, the following values of $\mathrm{N} \times e$ are obtained, for ions produced by Röntgen rays :-

$$
\begin{aligned}
& \text { Air . . . . } 1.3510^{-10} \\
& \text { Oxygen . . . } 1 \cdot 2510^{-10} \\
& \text { Carbonic Acid . . 1.30 10 } 10^{-10} \\
& \text { Hydrogen . . 1.07 10 } 10^{-10} \text {, }
\end{aligned}
$$

* E. Rutherford, Phil. Mag. November 1897.

+ J. Zeleny, Phil. Trans. vol. cxcv. pp. 193-234 (1900).

$\mp$ E. Rutherford, Cambridge Philosophical Society Proc. vol. ix. pt. viii, (1898).

J. S. Townsend, Phil. Trans. rol. exciii. (1899) and vol. exev. (1900). 
the mean value of $K$ for positive and negative ions being used.

From the values of $u$ and $\mathrm{K}$ for ions in air produced by ultra-violet light

$$
\mathrm{N} e=1 \cdot 12 \quad 10^{-10} \text {. }
$$

The following table of values of $\mathrm{N} \times e \times 10^{10}$ may be deduced from Prof. Zeleny's determinations of the velocities:-

\begin{tabular}{|l|c|c|c|c|}
\hline & $\begin{array}{c}\text { Positive ions } \\
\text { in moist gas. }\end{array}$ & $\begin{array}{c}\text { Negative ions } \\
\text { in moist gas. }\end{array}$ & $\begin{array}{c}\text { Positive ions } \\
\text { in dry gas. }\end{array}$ & $\begin{array}{c}\text { Negative ions } \\
\text { in ciry gas. }\end{array}$ \\
\hline Air ............. & 1.28 & 1.29 & 1.46 & 1.31 \\
Oxygen........... & 1.34 & 1.27 & 1.63 & 1.36 \\
Hydrogen ...... & 1.24 & 1.18 & 1.63 & 1.25 \\
Carbonic Acid... & 1.01 & .87 & .99 & .93 \\
\hline
\end{tabular}

The mean values of $\mathrm{N} \times e$ for the different gases are

$$
\begin{aligned}
& \text { Air . . . . } 1 \cdot 2710^{-10} \\
& \text { Oxygen . . . 1.32 10 } 10^{-10} \\
& \text { Carbonic Acid . . 1.13 10 } 10^{-10} \\
& \text { Hydrogen . . . } 1 \cdot 20 \quad 10^{-10} \text {. }
\end{aligned}
$$

In addition it has been shown that the values of $u$ and $\mathrm{K}$ for ions in air are both inversely proportional to the pressure for pressures between 760 and 200 millimetres.

The discrepancy between the above numbers is not greater than the prohable experimental errors, and they afford evidence of the equality of the charges. There is also evidence from other investigations which leads us to believe that the above values of $\mathrm{N} \times e$ should all be equal. This may be deduced from experiments on the ionization of molecules produced by collision, which are of a much simpler kind than the experiments which are necessary for the determination either of the velocities or the rates of diffusion.

It has been shown* that the negative ions produced in gases by the action of Röntgen rays or by collisions are all exactly the same as the ions set free from a zinc plate by the action of ultra-violet light.

In order, therefore, to obtain the most probable value of $N \times e$ we are justified in taking the mean of the above

$$
\text { * J. S. Townsend, Phil. Mag. June 1902. }
$$


numbers, since there is strong evidence to show that the differences must be due to experimental errors. The value of $\mathrm{N} \times e$ thus obtained is

$$
\mathrm{N} \times \epsilon=1 \cdot 23 \times 10^{-10} \text {, }
$$

$e$ being the charge on an ion in a gas.

It has been pointed out that $\mathrm{N} \times \mathrm{E}=1.22 \quad 10^{-10}$ where $\mathrm{E}$ is the charge on a hydrogen ion in a liquid electrolyte; and hence we see that the charges on ions in gases produced $b y$ various methods are equal to the charge on a hydrogen ion in a liquid electrolyte. This result depends only on the value of the product $\mathrm{N} \times e$, and it is not necessary to rely on the determinations which have been made of these quantities separately in order to obtain a proof of the proposition.

The determinations which have been made of $\mathrm{N}$ and $e$ vary over considerable ranges, and what are considered to be the most probable values of these quantities do not give the product $\mathrm{N} \times e=1.23 \times 10^{10}$. If one of the quantities could be determined the other would follow, since the product is known accurately; but it is difficult to decide which has been found with the greater accuracy, as in both cases there are weak points in the assumptions which are made, and in addition there is considerable experimental error in the determination of the charge $e$. Nevertheless, it is not unsatisfactory to find that the product only differs by a factor of about 3 from the number $1.23 \times 10^{10}$.

Lord Kelvin* has recently passed in review the various methods which have been employed to determine $\mathrm{N} t$, the number of molecules in a cubic centimetre of a gas at $0^{\circ} \mathrm{C}$. and standard atmospheric pressure.

From the calculations he has made it seems more probable that $10^{20}$ is nearer to the true value of $\mathrm{N}$ than $8.9 \times 10^{19}$, and it is not improbable that the true value is greater than $10^{30}$. This number is dednced from the coefficient of viscosity of argon and from its densities in the liquid and gaseous states. Using the formula $\mathrm{NE}=1 \cdot 2210^{10}$, it is seen that $1 \cdot 2210^{-10}$ is not improbably an upper limit to the values of the charge in electrostatic units.

The following are the values of $e$ found experimentally by different observers :-

* Lord Kelvin, Phil. Mag. August \& September 1902.

+ This number is about $\tilde{5}$ per cent. greater than the value of $N$ with which we have been dealing, which refers to $15^{\circ} \mathrm{C}$. and standard atmospheric pressure. 
Prof. J. S. Townsend on Charges on Ions.

\begin{tabular}{|c|c|c|}
\hline $\begin{array}{l}\text { Value of } e \text { in } \\
\text { electrostatie units. }\end{array}$ & $\begin{array}{l}\text { Method of generating } \\
\text { the ions. }\end{array}$ & Observer. \\
\hline $\begin{array}{llll}3.0 & 10-10 & . .\end{array}$ & $\begin{array}{l}\text { Ions in oxygen pre- } \\
\text { pared by electro- } \\
\text { lysis. }\end{array}$ & $\begin{array}{l}\text { J. S. Townsend, Proc. } \\
\text { Camb. Phil. Soc. } \\
\text { vol. ix. pt. v., } 1897 .\end{array}$ \\
\hline $6510-10$ & Röntgen rays. & $\begin{array}{l}\text { J. J. Thomson, Phil. } \\
\text { Mag. Dec. } 1898 \text {. }\end{array}$ \\
\hline $6810-10 \ldots$ & $\begin{array}{l}\text { Negative ions pro- } \\
\text { duced by ultra- }\end{array}$ & $\begin{array}{l}\text { J. J. Thomson, Phil. } \\
\text { Mag. Dec. } 1899 \text {. }\end{array}$ \\
\hline $3+10-10$ & Radium. & $\begin{array}{l}\text { J. J. Thomson, Phil. } \\
\text { Mag. March } 1903 \text {. }\end{array}$ \\
\hline $3 \cdot 110-10$ & Röntgen rays. & $\begin{array}{l}\text { H. A. Wilson, Phil. } \\
\text { Mag. April } 1903 .\end{array}$ \\
\hline
\end{tabular}

With regard to the differences between his determinations, Prof. Thomson states in his recent paper: "The mean of these values gives $3.4 \times 10^{-10}$ as the charge in electrostatic units of the gaseous ion. This is about half the value $6.5 \times 10^{-10}$ I found in the earlier experiments. The difference is, as I have already explained, due to the expansions in the earlier experiments practically catching only the negative ions; this made the calculated value of $n$ little more than half the true value, while it made the value of $e$ twice as great as it ought to have been." The number $n$ denotes the number of drops in the cloud formed by expanding the moist gas containing the ions. It appears fiom Mr. C.T. R. Wilson's experiments, that condensation of moisture takes place round negative ions for a slightly smaller expansion than is required to produce condensation round positive ions*. This may be the cause of the discrepancy between the experiments with radium radiation which give the value $3 \cdot 410^{-10}$ and those which were first made by Prof. Thomson with Röntgen rays. The explanation does not, however, explain the difference hetween the value $3 \cdot 410^{-10}$ and the value $6.810^{-10}$ which was obtained for the charge on the ions produced by the action of ultra-violet light. In the latter case no positive ions were present in the gas, and the number $6.810^{-10}$ was obtained from considerations of the presence of negative ions alone.

The mean of the values, omitting the value $6.5 \times 10^{-10}$ for Röntgen rays, comes to $4.1 \times 10^{-10}$.

Of the numbers in the table, that found by $\mathrm{Dr}$. H. A. Wilson is probably the most reliable, and more weight ought to be given to his determination. By the method which he used he avoids the necessity of finding the number of drops in the cloud formed by the expansion of the conducting gas,

* C. T. R. Wilson, Phil. Trans. vol. cxciii. p. 289. 
and a very uncertain quantity is thus eliminated from his calculations. Dr. Wilson concludes from his experiments that "it may be considered established that $e$ lies between $2 \times 10^{-10}$ and $4 \times 10^{-10}$ E.S. units." The lower limit is in fair agreement with the value $1 \cdot 2 \quad 10^{-10}$ found for $\mathbf{E}$ by taking $\mathrm{N}=10^{20}$. We see, therefore, that the value $2 \times 10^{-10}$ does not differ by more than the factor 2 from the most probable values which can be obtained by both methods.

\section{The Conductometer. By Rollo APPLeyard*.}

$r$ THIS is a direct-reading instrument, intended for the comparison of electrical conductivity $\dagger$ of copper and other wires, for a range within, say, 5 per cent. above and 5 per cent. below 100 .

In comparing two wires, either may be regarded as the standard. Suppose that balance is obtained with two samples of equal length upon a straight bridge-wire, divided into 100 parts, the position of balance being $L$ divisions: (A) assuming the two wires to be of the same mear diameter, but of different conductivities; (B) assuming the wires to be of equal conductivity, but of unequal diameters. In case (A) it is found from the conditions of balance that a change of 1 per cent. conductivity between +5 per cent. and -5 per cent. corresponds on the average with $\frac{1}{400}$ of the total length of the bridge-wire. If therefore the middle of the bridge-wire is marked " 100 " and divisions are marked off from that point to right and left, each equal to $\frac{7}{400}$ of the length of the bridge-wire, these approximately correspond to successive increments of 1 per cent. conductivity. Or again, if the standard wire is not 100 per cent., move the whole scale thus graduated so that the mark on it corresponding to the conductivity of the standard is in coincidence with the electrical middle of the bridge-wire. I have proved that this arrangement is still direct-reading, and that its indications may be trusted to within a considerable degree of accuracy.

In case (B), suppose the two wires have diameters $d$ and $(d+y)$ respectively. Then an expression for $L$ in terms of $y$ and $d$ can be found. If in this expression $y$ is given some definite value, say $1 \mathrm{mil}$, and if $d$ is then given successive values corresponding to the whole range of diameters of wires in common use, a table or curve can be constructed showing at once the amount by which the slider must be

* Communicated by the Physical Society : read December 11, 1903.

+ See "The Electrical Conductivity of Copper," Electrical Review, June 19, July $3 \& 10$, and August 14, 1903. 